\title{
Management of the urban spatial setting to determine the effect of urban heat island on the Bangkok Metropolis, Thailand
}

\author{
S. Chavanavesskul \\ Urban and Environmental Planning Program, \\ King Mongkut's Institute of Technology Ladkrabang, Thailand \\ Department of Geography, Srinakharinwirot University, Thailand
}

\begin{abstract}
Urbanization and human activities cause higher air temperatures in urban areas than the urban climate. This study uses remote sensing data to observe this urbanization and its surrounding areas. The high temperature can cause problems to the environment, such as high energy consumption on cooling, raised air pollution levels and changes in land use and the creation of a heat island in Bangkok Metropolis, Thailand. This study found that the urban heat island (UHI) problem is caused by the large size of the urban area and sparse vegetation and water resources. Some strategies and approaches are raised in this paper in order to reduce the problem.
\end{abstract}

Keywords: urban heat island (UHI), GIS.

\section{Introduction}

\subsection{Issue and problems statement}

Because of urbanization, many cities in the world are suffering from many environmental problems. The urban heat island (UHI) is one of the problems that are caused by urbanization. Monitoring of the temperature in the area has revealed that it is estimated to increase by $2-3^{\circ} \mathrm{C}$ every year. In addition, the global population has increased six times during the last two hundred years urban population has grown 128 times (Emmanuel [20] refer to cf. Schell, et al. 1993). Therefore, the global urban population is expected to outnumber the rural 
population (Oke [16]). The urbanization phenomenon has happened less in developing countries than in developed countries.

The pattern of city growth is dynamic and rapid (increasing in size), due to the urban population increasing and an uneven distribution pattern of resources to support life. This brought about the concentration of population and changing of the existing land use in the city: green areas (agriculture, vegetation, open space), and wet lands have been transferred to residential, commercial, and industrial areas. The decreasing of open space also reduces the level of humidity in the atmosphere. The construction in tropical cities did not take into account the style, height and orientation of buildings in relation to the direction of the prevailing wind. Some buildings block wind and reflect solar radiation amongst the buildings, wall, and ground, depending on the respective materials of the buildings and streets. Dark colours, roughness and matt materials absorb heat yet are unable to reflect radiation as well as light colours, smooth and shiny material. Human activities, such as travelling and construction, generate dust and smog, which blocks ventilation. All these factors together contribute towards a phenomenon called "heat island".

The heat island phenomenon increases the already high temperature of the city even further, which is brought about by air and water pollution and changes in human activities. People do not want to be exposed to the outdoor environment; they would prefer to live inside buildings and with airconditioning. These patterns of living further increase energy consumption (electric, water and petroleum) and deteriorate the health condition of citizens in the city.

This research aims to study the nature of the heat island in Bangkok Metropolis, analyzing the relationship between the pattern of land use and the heat island attributes. It aims to elucidate the process, the pattern and the impact of the heat island phenomena to find an appropriate strategy and approach to control the environment exploiting the heat island pattern.

\subsection{Objectives of the study}

The objectives of the study are:

1. To study the process and pattern of the heat island phenomenon under the context of the Bangkok Metropolis.

2. To derive a means by which to manipulate the heat island phenomenon to reduce temperature, energy consumption and pollution under the context of the Bangkok Metropolis.

3. To find a strategy and approach to managing the environment under the context of the Bangkok Metropolis.

\subsection{Scope of the study}

The UHI problem in this paper will be addressed in the Bangkok Metropolis and its surrounding provinces, which are representative of urban, suburban and rural areas. The size of cities is determined by areas of continuous structures without 
other separate land use, especially agriculture, recreation and parks; water resources are used as the boundary line.

In addition, this study is limited by satellite-image data (LANDSAT 5-TM and SPOT) because of the lack of prospected data (different periods of satelliteimage data). This may cause some difficulties in comparing and analysing data. Likewise, time and budget limitations are taken into an account in order to reach completion of the study. Thus, the selected study area and field survey strategies are applied in this research.

\subsection{Definition}

The UHI: a reflection of the micro-climate changes brought about by human alterations to the earth's surface in densely populated areas. It is a good indicator of the sensitivity of the climate system to human interference on a local level. It is a complex, site and episode-specific phenomenon and can vary in time and space.

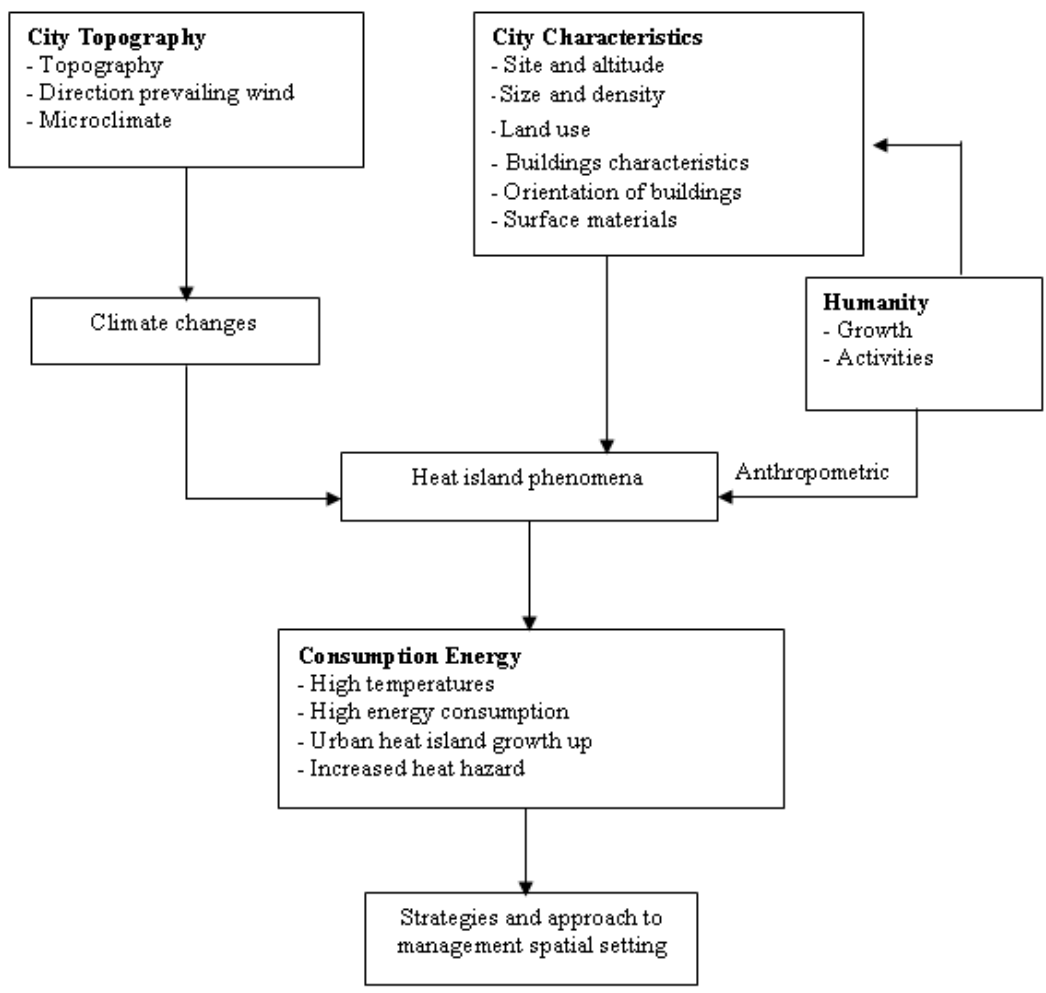

Figure 1: Conceptual framework. 


\section{Methodology}

The following methodology applied in the study forms the basis of reference towards the objective of the study, whereby it is aimed at researching the process and pattern of the heat island under the context of the Bangkok Metropolis.

1. Collection of primary microclimate data.

1.1 In order to acquire existing temperature data in the study area, three automobile thermographs (OPUS-200) were installed in three vans. These vans were driven on assigned routes in order to explore temperature. The temperature collecting time in this study is 10 p.m., which is assumed to be at least four hours after sunset. It is the highest heat period in a day because of the diffuse to air temperature.

1.2 Explore temperatures in different periods of the week. This research selected two representing days of the week - a weekday and a weekend. Wednesday is represented as a weekday, which is representative of the most accumulated energy in a day, whereas Sunday is represented as a weekend, which is representative of the least accumulated energy in a day.

1.3 The position level of the sensor thermograph is 150 centimetres from the ground. 1.4 Determine three routes that cover the study area, Route 1 is north to south, Route 2 is lower east to west and Route 3 is upper east to west. The assigned route map is shown in figure 2 .

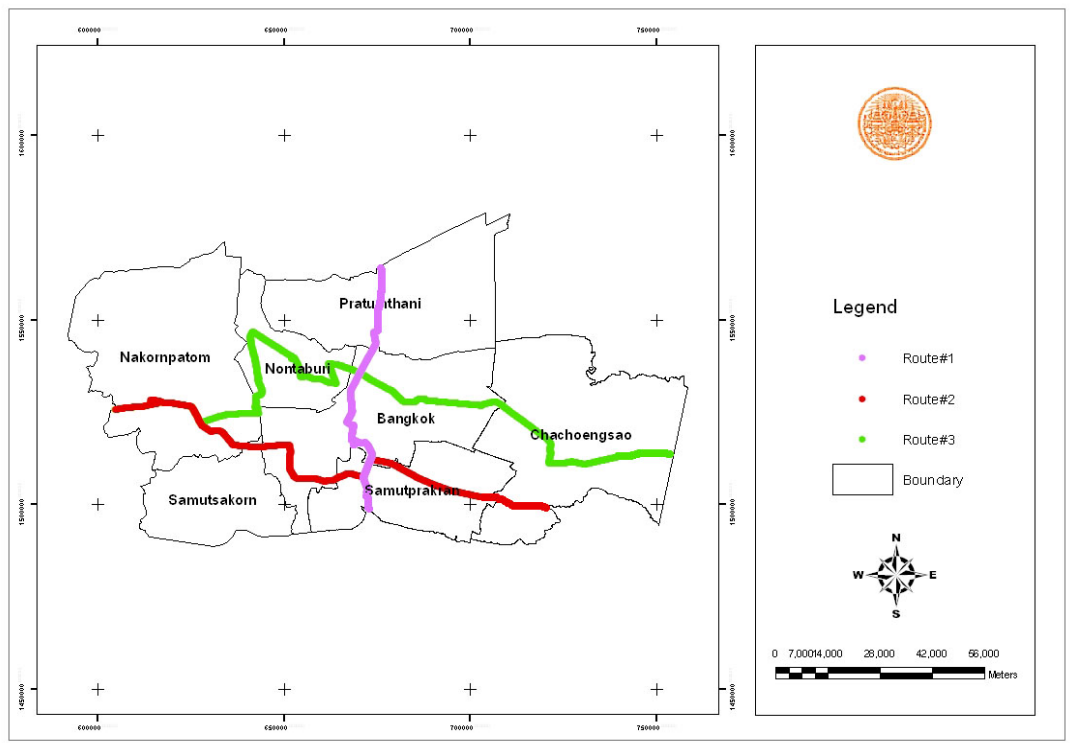

Figure 2: $\quad$ The assigned route map for collecting temperature data.

2. Collection of secondary data.

2.1 Secondary data were gathered from related documents.

2.2 Interpretative satellite imagery from LANSAT 5-TM and SPOT is used to characterize land use during 1987, 1997 and 2007 and compared for accuracy by 
using a ground truth sample. Use of binominal probability theory to sample at least an error percentage of points (36 points, as shown in figure 3 ) and sampling of imagery points by cluster sampling (Campbell [4]) Checking the overall accuracy of data (LANDSAT 5, January 5 2007) by confusion matrix (Congalton [21]) is $86.11 \%$.

3. Analysis data.

3.1 Analyse satellite imagery to characterize the heat island effect in the study area with a geographic information system (GIS).

3.2 Compare heat island areas by size, pattern and features of cities. Derive a means by which to manipulate the heat island phenomena to reduce temperature, energy consumption and pollution.

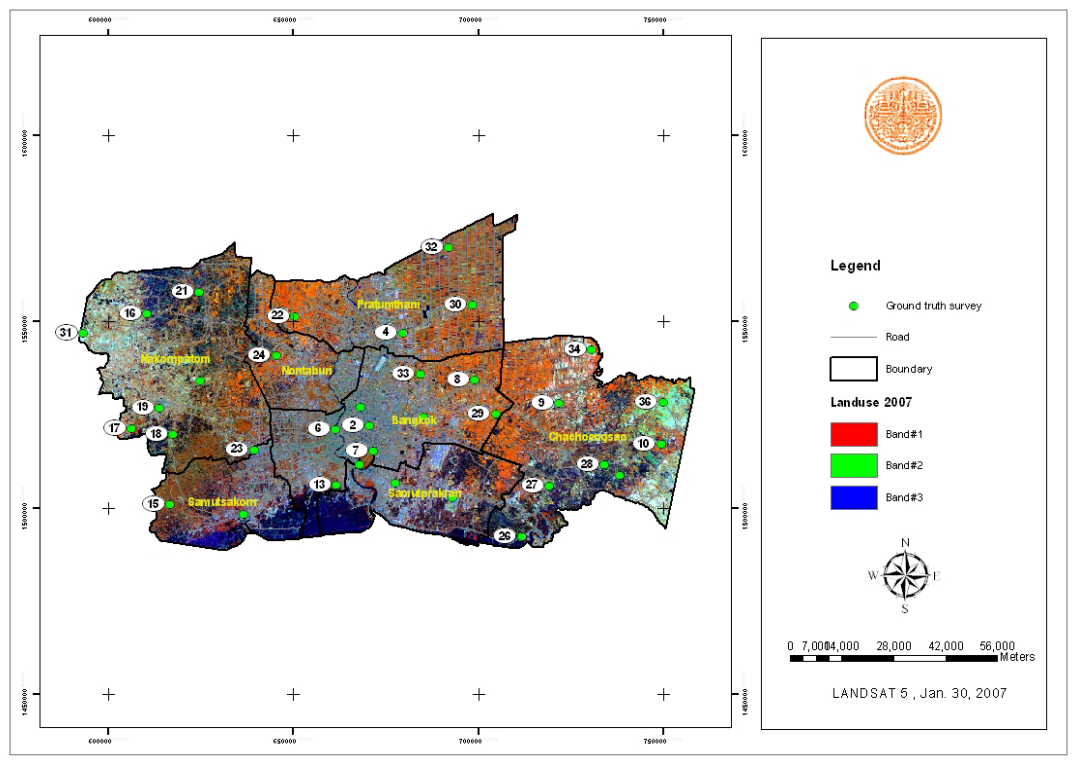

Figure 3: $\quad$ Map of ground truth survey 36 points.

Table 1: Land use change in Bangkok Metropolis and its surrounding provinces between 1987 and 2007.

\begin{tabular}{|c|c|c|c|c|c|c|c|c|c|}
\hline & \multicolumn{3}{|c|}{ Land use $\left(\mathrm{Km}^{2}\right)$} & \multicolumn{6}{|c|}{$\Delta$ Land use } \\
\hline & \multirow{2}{*}{1987} & \multirow{2}{*}{1997} & \multirow{2}{*}{2007} & \multicolumn{2}{|c|}{$1987-1997$} & \multicolumn{2}{|c|}{$1997-2007$} & \multicolumn{2}{|c|}{$1987-2007$} \\
\hline & & & & $\mathrm{Km}^{2}$ & $\%$ & $\mathrm{Km}^{2}$ & $\%$ & $\mathrm{Km}^{2}$ & $\%$ \\
\hline Urban and commercial & 624.318 & 725.485 & 932.417 & +101.167 & +16.204 & +206.932 & +28.523 & +308.099 & +49.350 \\
\hline Residential & 737.125 & 997.430 & $1,729.798$ & +260.305 & +35.314 & +732.368 & +73.426 & +992.673 & +134.668 \\
\hline Inchustrial & 71.908 & 93.484 & 194.298 & +21.576 & +30.005 & +100.814 & +107.840 & +122.389 & +170.201 \\
\hline Agriculture & $7,933.490$ & $7,665.989$ & $6,553.260$ & -267.501 & -3.372 & $-1,112.73$ & -14.515 & $-1,380.230$ & -17.398 \\
\hline Park and recreation area & 5.188 & 7.051 & 12.140 & +1.863 & +35.921 & +5.089 & +72.169 & +6.952 & +134.013 \\
\hline Forestry & 163.023 & 67.102 & 91.000 & -95.921 & -58.839 & +23.898 & +35.614 & -72.023 & -44.180 \\
\hline Water resource & 187.596 & 136.266 & 108.556 & -51.371 & -27.384 & -27.669 & -20.311 & -79.040 & -42.133 \\
\hline Open space & 5.625 & 35.507 & 106.806 & +29.882 & +531.211 & +71.299 & +200.802 & 101.181 & $+1,798.696$ \\
\hline
\end{tabular}

Remark: $\triangle$ Land use calculates by areas different between 1987-2007 in each land uses

+ Increase land use

- : Decrease land use 


\section{Results and discussion}

\subsection{Land use changes over 20 years (1987-2007)}

The study area is 9,728.275 sq. kilometres. Land use can be divided into eight types: urban and commercial, residential, industrial, forestry, parks and recreation areas, agriculture, water resources and open spaces.

Table 1 shows the land use changes from 1987 to 2007 . The three types of land use have increased during the study period; urban and commercial areas, residential areas, and industrial areas - 49.35\%, 134.69\%, and $170.20 \%$, respectively. These land uses were relative to main transportation by cluster along the Chao Phraya River. At present, they are distributed along roads and almost expand to south of the Bangkok Metropolis close to the Samutprakarn province and west of the Bangkok Metropolis close to the Nakornpatom province and Samutsakorn province.

On the other hand, agriculture areas, forestry areas and water resource areas have decreased during the same time - $17.40 \%, 44.18 \%$, and $42.13 \%$, respectively. These areas have become urban and commercial, industrial and residential areas as a result of the population's demands.

\subsection{Size and features of the city effect the pattern of heat island phenomenon}

The size and features of the city affect the clusters of heat and the pattern of the heat island, such that the large cities (Bangkok Metropolis, Nonthaburi and Samutprakarn) and medium city (Nakornpatom) affected by the UHI phenomenon have similar air temperatures (isothermals), but different UHI locations and frequency of isothermals. In the large cities (Bangkok Metropolis, Nonthaburi and Samutprakarn) UHI was detected in many locations, because these cities are very built up (the main material surfaces are concrete and glass). On the other hand, within the small city (Chachoengsao) the UHI was detected less than in the large cities and medium city.

Figures 4 to 6 show an isothermal map of the large cities, a medium city and a small city. These maps were created based on the field survey of two representative periods; the weekend was collected on Sunday 10th March 2007 at 10 p.m. and the weekday was collected on Wednesday 12th March 2007 at 10 p.m. From these figures it can be seen that the large and medium cities had similar temperatures; their temperature on the weekday (Wednesday) and the weekend (Sunday) differed by about $1.5-2^{\circ} \mathrm{C}$. The small city had different temperatures from the large and medium cities by about $1-3^{\circ} \mathrm{C}$; its temperature on the weekday (Wednesday) differed by about $2-3^{\circ} \mathrm{C}$ and the weekend (Sunday) differed by about $1-1.5^{\circ} \mathrm{C}$. This is because almost all of the material surfaces in the small city are vegetation and water resources (which provide more humidity than concrete and glass). The highest temperature in a day was created at 9.3011.00 p.m.; on the weekday (Wednesday) the detected temperature was $29.44^{\circ} \mathrm{C}$ and on the weekend (Sunday) it was $28.78^{\circ} \mathrm{C}$. This was obtained at the centre of the study area located in the Bangkok Metropolis in the Bangna-Trad zone and 


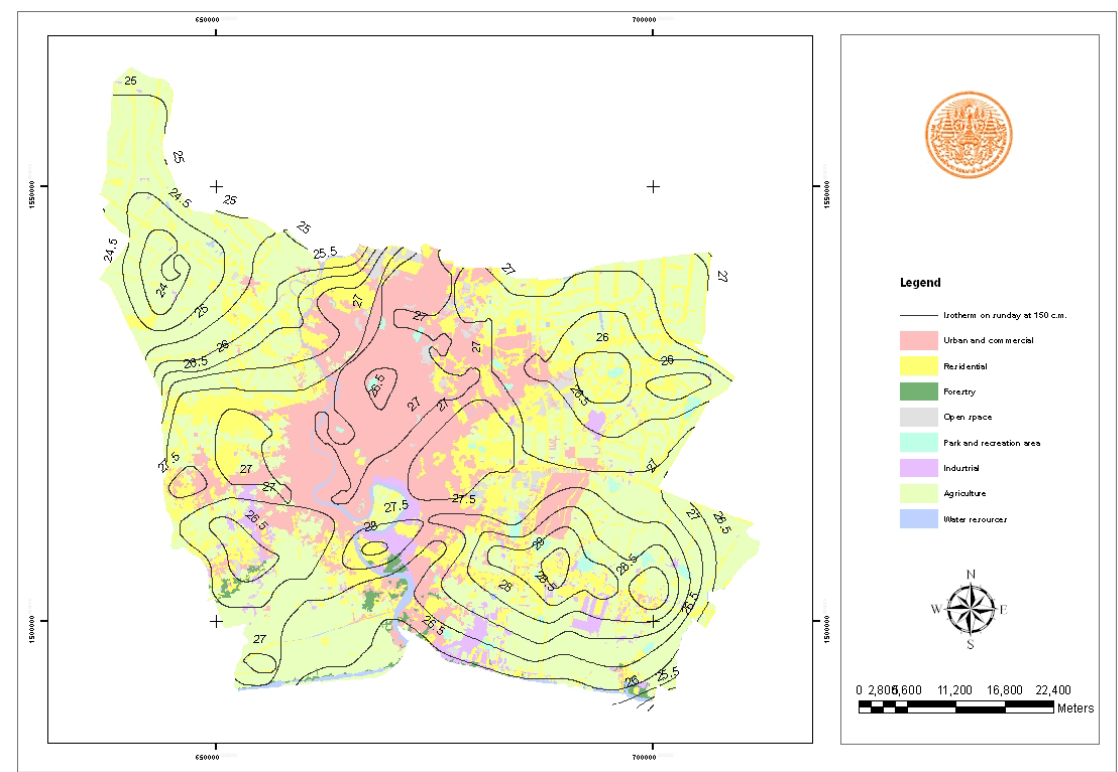

(a)

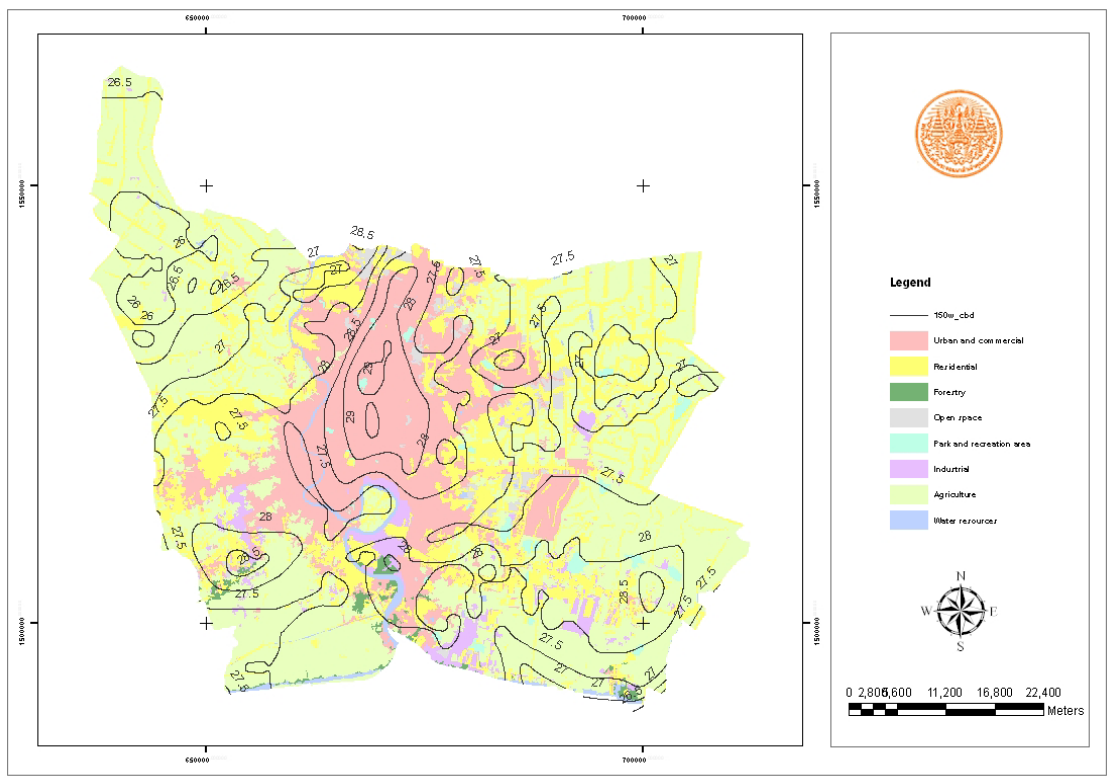

(b)

Figure 4: The large city: Bangkok Metropolis, Nonthaburi and Samutprakarn: (a) on March 10, 2007 (Sunday) at 10 p.m.; (b) on March 12, 2007 (Wednesday) at 10 p.m. 
60 Sustainable Development and Planning IV, Vol. 1

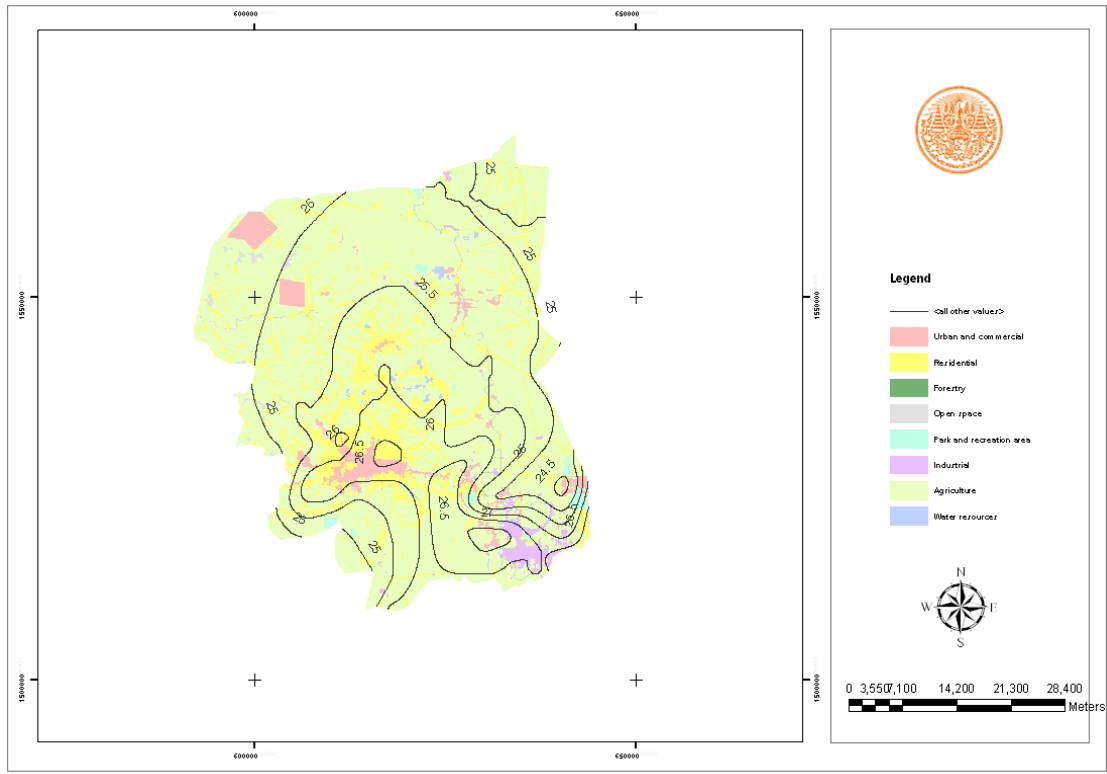

(a)

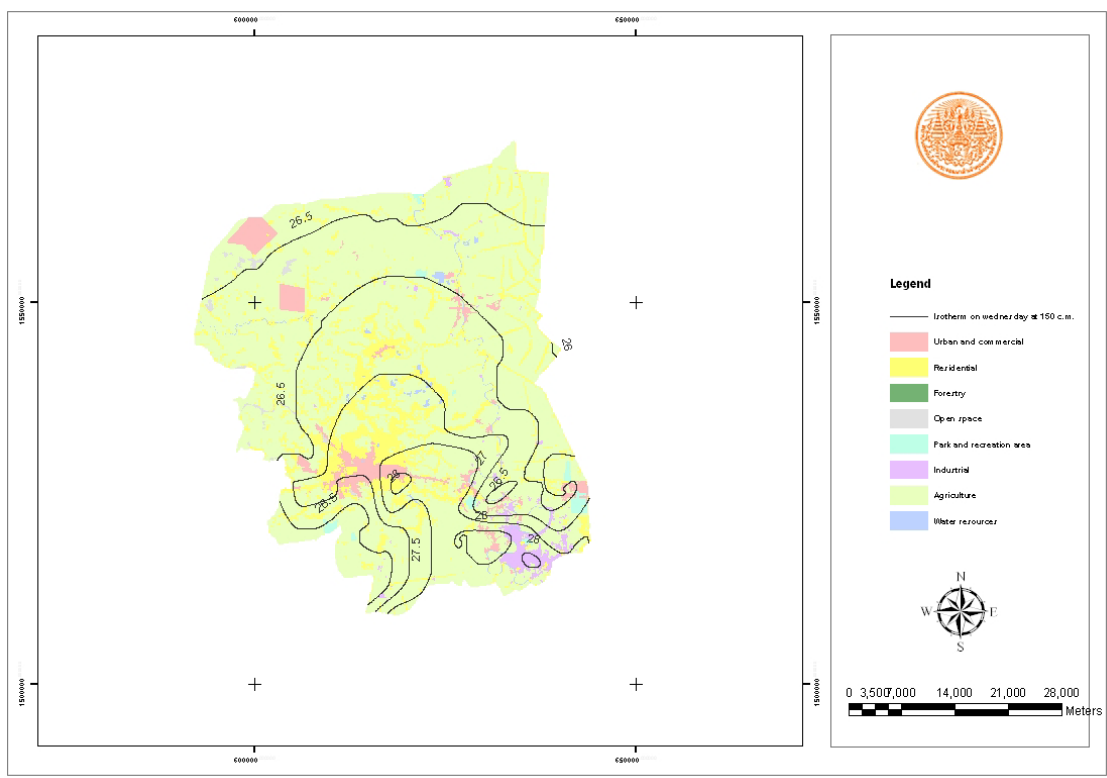

(b)

Figure 5: The medium city: Nakornpatom: (a) on March 102007 (Sunday) at 10 p.m.; (b) on March 12, 2007 (Wednesday) at 10 p.m. 


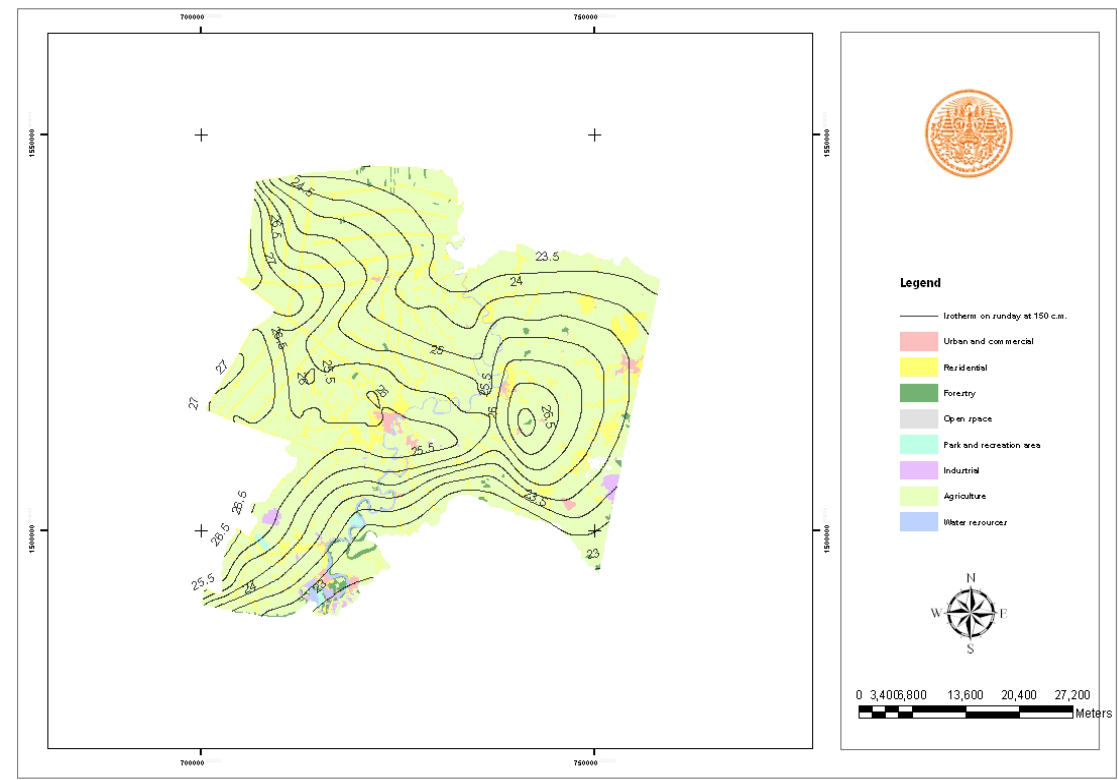

(a)

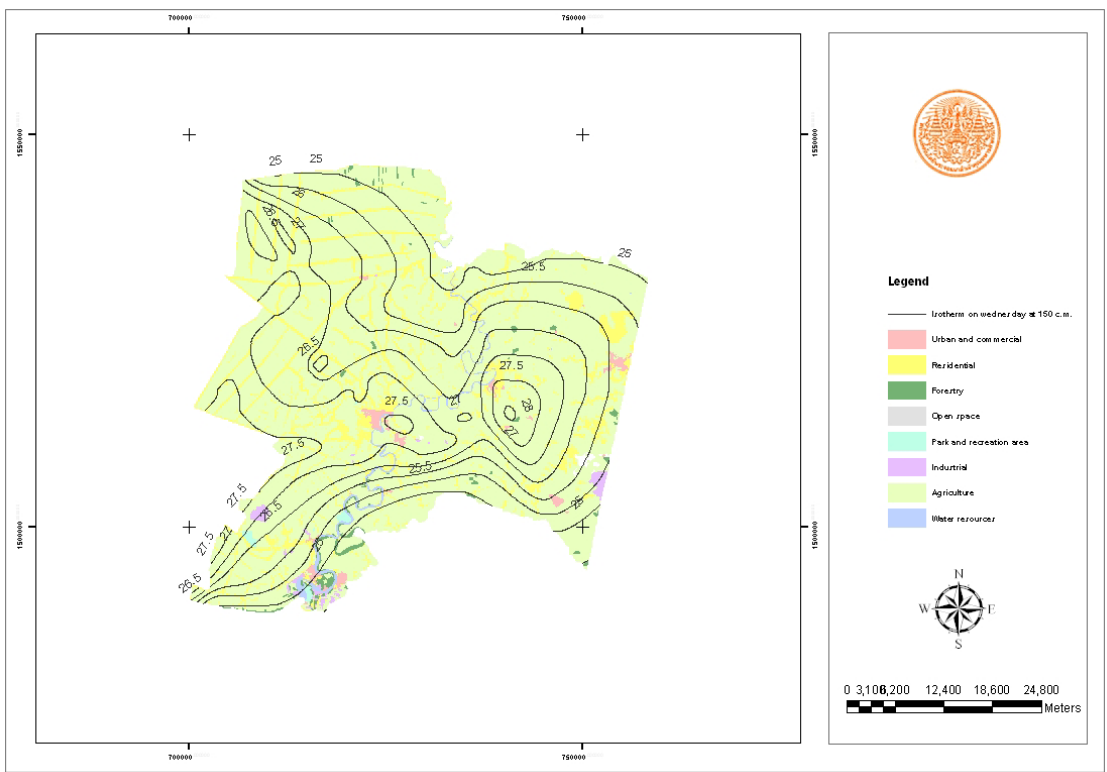

(b)

Figure 6: The small city: Chachoengsao: (a) on March 10, 2007 (Sunday) at 10 p.m.; (b) on March 12, 2007 (Wednesday) at 10 p.m. 
the Vipavadee-Rangsit zone. In green and humid areas (forestry, parks and recreation areas), the detected temperature was $27.5^{\circ} \mathrm{C}$ and the lowest temperature found in agriculture and water resource areas was $23^{\circ} \mathrm{C}$.

Thus, UHIs are located in built up areas of cities, where almost all of their features are concrete, asphalt and glass, such as urban and commercial areas, residential areas and industrial areas.

\subsection{Managing the heat island in the urban context}

This study found that almost all UHI areas occurred where there was a lack of vegetative and humid areas. When the size of cities is compared, it was found that large and medium cities have heat emitting rates that are slower than those of the small city, because the small city has less bulk of built up areas and many vegetative and humid areas. In terms of UHI management strategy, the heat island phenomenon should be determined particularly in urban and surrounding areas. The related authorities should recognize and set policies in order to reduce UHI problem. For example, the provision of a buffer of green and humid areas, and more green activity areas such as parks and recreation areas contribute to a cities' green network. Construction standards should be set such that surface material for construction should be light coloured and smooth.

\section{Conclusions}

The UHI effect is a complex, site-specific phenomenon and can therefore vary in time and place. Many factors can alter the strength of the UHI effect on any day or in any location. Some of these factors include: season, weather conditions, urban characteristics, and anthropometric heat. Heat islands develop in areas that contain a high percentage of water-resistant surfaces and a low percentage of vegetation and humidity surfaces. Both the city's size difference and continued development of built up areas may increase the heat island conditions.

\section{References}

[1] Anthony J. Brazel. et al. "CAP LTER Climate". Arizona: Arizona State University. 2001.

[2] Aya Hagishima. et al. "An Intrigued Analysis to Quantify the Cause for Urban Heat Island". Japan: The Revised Architecture-Urban-SoilSimulation Model (AUSSSM), Kyishu University. n.d.

[3] Benjamin Stien and John S. Reynolds. "Thermal Control". Mechanical and Electrical Equipment for Building. 8thed. Oregon: John Wiley \& Sons. n.d.

[4] Campbell, J.B. "Introduction to Remote Sensing". 2nd ed. New York: The Guilford Press. 1996.

[5] Christopher Small and Roberta Balstad Miller. "Monitoring the Urban Environment from Space". New York: Columbia University. n.d. 
[6] C.J.G. (Jon) Morris. "Urban Heat Islands and Climate Change": Melbourne, Australia. School of Earth Sciences. Australia: The University of Melbourne. n.d.

[7] C.J.G. (Jon) Morris. "Urban Heat Island in Small Towns": Deniliquin, Australia. School of Earth Sciences. Australia: The University of Melbourne. n.d.

[8] Floyd F. Sabin Jr. "Thermal Infrared Imagery". Remote Sensing: Principles and Interpretation. 3rded. Los Angeles: Remote Sensing Enterprises Incorporated and University of California. 1996.

[9] F. Pignolet-Tardan. et al. "Modelling of the Urban Heat Island Generated by an Urban Unit". France: Centre de Thermique de l'Insa de Lyon (CETHIL). n.d.

[10] George B. Magin, Jr., and Lois E. Randall. "Review of Literature on Evaporation Suppression". Studies of Evaporation. n.p. n.d.

[11] Giulia Abbate. "Heat Island study in the area of Rome by integrated use of GRS-SAR and Landsat TM". Italy: ENEA-Casaccia, Environment Department. n.d.

[12] Kohei Minakuchi. "Urban Heat Island". East St. Louis Action Research Project. University of Illinois at Urbana-Champaign. 2001.

[13] Paul R. Baumann. "An urban Heat Island". Washington D.C. New York: Department of Geography, State University of New York, College at Oneonta. 2001.

[14] Robert T. Watson, editor. "IPCC Third Assessment Report". Climate Change 2001 Synthesis Report. Stand-alone edition. A Report of the Intergovernmental Panel on Climate Change. 2001.

[15] Stanley Q. Kidder and Jan Hafner. "Urban Warming: A Satellite, Modelling, and Climatological Study, Huntsville" The University of Alabama. n.d.

[16] T.R. Oke. "Boundary Layer Climates". London. 1978.

[17] Gallo K.P. et al. The Use of NOAA AVHRR Data for Assessment of the Urban Heat Island Effect 'Journal of Applied Meteorology', volume 32, issue 5, 899-908. 1992.

[18] G.R. Chhatwal. Management of Prevention of Thermal Pollution. 'Encyclopaedia of Environmental Management', volume 2, India. 1998.

[19] Jari Niemela. Ecology and urban planning. 'Kluwer Academic Publishers', volume 8, issue 119-131. Netherlands: Department of Ecology and Systematics, Biodiversity and Conservation. 1999.

[20] Martin de Porres Rohinton Emmanuel, Summertime heat island effects of urban design parameters. A dissertation for the degree of Doctor of Philosophy (Architecture), The University of Michigan. 1997.

[21] Congalton, R.G. A view of assessing the accuracy of classification of remotely sensed data. Remote Sensing Environment. 37 (1): 35-46., 1991. 